\section{Conceptual and methodological aspects of relations between discrimination and health in epidemiological studies}

\author{
Aspectos conceituais e metodológicos das \\ relações entre discriminação e saúde \\ em estudos epidemiológicos
}

\footnotetext{
1 Programa de Pósgraduação em Saúde Coletiva, Universidade Federal de Santa Catarina, Florianópolis, Brasil. 2 Instituto de Medicina Social, Universidade do Estado do Rio de Janeiro, Rio de Janeiro, Brasil.

Correspondence J. L. Bastos

Programa de Pósgraduação em Saúde Coletiva, Universidade Federal de Santa Catarina. Campus Universitário Trindade, Florianópolis, SC 88010-970, Brasil. joao.luiz.epi@gmail.com
}

\begin{abstract}
This article addresses conceptual and methodological aspects of the relations between discrimination and health from an epidemiological perspective. Definitions of discrimination and related constructs are reviewed, and the main theories underlying their association with health are presented. Scales developed to assess discrimination are discussed, in conjunction with a new instrument, devised to operationalize the concept in Brazilian epidemiological surveys. As a relatively unpredictable and uncontrollable source of psychosocial stress, discrimination has been consistently associated with adverse health outcomes and behaviors, particularly mental disorders, smoking, and alcohol use. However, progress in the area depends partly on dealing with aspects related to the assessment of the phenomenon, such as the definition of a construct map and simultaneous measurement of different types of discrimination. Research involving these aspects will enhance our understanding of discrimination and its health consequences, thus increasing our ability to reduce its social occurrence.
\end{abstract}

Prejudice; Epidemiologic Studies; Causality; Health Status; Psychometrics
João Luiz Bastos 1

Eduardo Faerstein 2

\section{Introduction}

Any approach to the phenomenon of discrimination in epidemiological studies poses huge challenges to interested researchers. The focus could be to present an updated overview of empirical studies on the pathogenic effects of experiences with discrimination for individuals and population groups. However, given the theme's embryonic nature in health research, the task also includes defining discrimination conceptually, besides discussing how it has been operationalized in health-related research.

Thus, the current study is organized in three basic parts:

1. The first expounds on the conceptual differences between discrimination, prejudice, and stereotype, from the perspective of social psychology, primarily North American in origin. Although these topics have a long history in the disciplines of anthropology and sociology, social psychologists were primarily responsible for developing systematic and nuanced analyses of these concepts, thus justifying the perspective adopted in the section;

2. Next, we present the state-of-the-art on relations between interpersonal discrimination and health conditions, highlighting the principal theories proposed to explain the epidemiological associations. Here, the point of departure is the set of literature reviews published since 2000 $1,2,3,4,5,6,7,8$; and 
3. The last section, based on a systematic literature review ${ }^{9}$ and the lead author's PhD dissertation 10 , discusses the available instruments for measuring discrimination and presents a proposal for its measurement in Brazilian epidemiological studies.

An initial caveat is in order: although the article's focus on interpersonal discrimination, it should not be grasped in isolation, disconnected from other equally relevant processes and their impact on health conditions. For example, a vast literature indicates that institutional discrimination (expressed in the form of spatial segregation ${ }^{11}$ ) and internalized racism 12 constitute other harmful health "exposures", commonly associated with interpersonal discrimination 7 . We urge readers to consult the publications cited above for access to detailed discussions of aspects not covered in the current article.

\section{Prejudice, stereotype, and discrimination}

The objective of this section is to present updated definitions for the terms prejudice, stereotype, and discrimination, so that the subsequent sections of the paper can be appreciated with greater conceptual precision. The literature on relations between discrimination and health conditions is partially characterized by a lack of terminological rigor 5. Authors sometimes refer to racism - a discursive apparatus that proposes a classification of humankind based on physical and biological characteristics 13 - when they should limit their explanations to the level of interpersonal relations, although influenced by a racist ideology. Likewise, many studies employ the terms prejudice and discrimination interchangeably when the phenomenon in question refers exclusively to discrimination.

One of the first definitions of prejudice was formulated by Gordon W. Allport in his seminal work The Nature of Prejudice, published originally in 1954. Allport defines prejudice as "an antipathy based on faulty and inflexible generalization. [According to the author, prejudice] may be felt or expressed. It may be directed toward a group as a whole, or toward an individual because he is a member of that group" 14 (p. 9). Yet what is probably one of the more current demarcations of the term comes from the recent work of Dovidio et al. 15 (p. 7), who define prejudice as "individual-level attitude (whether subjectively positive or negative) toward groups and their members that creates or maintains hierarchical status relations between groups".

Meanwhile, according to Taguieff 16, stereotype is expressed as a fixed idea, associated with a social category, which distorts, impoverishes, and oversimplifies reality. In this sense, a recent definition of stereotype considers it "set of qualities perceived to reflect the essence of a group; beliefs about the characteristics and attributes of a group and its members that shape how people think about and respond to thr group" 15 (p. 8).

Discrimination, in turn, is generally understood as a biased behavior that includes not only actions that bring harm or disadvantage to another group, but also those that unfairly favor the perpetrator's own group, generating relative disadvantages 15 . In the area of social psychology, interpersonal discrimination has currently been defined as "as behavior that creates, maintain, or reinforces advantage for some groups over other groups and their members" 15 (p. 10).

In short, discrimination refers to unfair treatment motivated by identity characteristics or the fact that one belongs to a specific group. As an exposure that is potentially harmful to health and perpetrated against individuals and social groups, discrimination is the concept most frequently operationalized in epidemiological studies, although with important limitations, as we shall see in a later section of this article.

\section{Discrimination and health conditions}

To a major extent (and especially in the first decades of its main development, namely since the 1980s), the epidemiological literature on discrimination examined the pathogenic effects of this exposure on health conditions and behaviors in the Black population in different research contexts in the United States 17. In addition, the research in this area was marked by studies on the relationship between discrimination and mental health conditions 1 , smoking, alcohol use and abuse 5,6,7, and cardiovascular outcomes, especially blood pressure 2,4 .

In recent years, however, there has been growing international interest in the theme, and studies have been conducted in populations in other countries, like New Zealand, Australia, and South Africa, in addition to immigrants in various European countries, involving a growing multiplicity of health outcomes 6,7 . The range of target health conditions has varied extensively, including for example pelvic inflammatory disease, diabetes, fungal infections, respiratory conditions, uterine miomas, breast cancer, abdominal obesity, illicit drug use, sleep disorders, satisfaction with health services, and adherence to medical prescriptions ${ }^{7}$. The focus was also expanded in the types of discrimination evaluated, no longer limited to behaviors with exclusively 
racist motives. Research has also come to include (although not simultaneously) 17 discriminatory treatments attributed to mental disorders, such as schizophrenia, and sexual orientation, especially homosexuality.

In the context of this growing scientific output, there has been a reasonably consistent observation of associations between discrimination and adverse health conditions, assessed with different methodological strategies and in various socio-cultural contexts. In the midst of a diversity of focuses and methods, it is equally noteworthy that the theoretical frame of reference for interpreting these associations is relatively uniform among the authors. Most of the studies interpret experiences of discrimination as a specific form of stress for the victims, and from this perspective, they give meaning to the empirically produced associations.

\section{Theories on the adverse health effects of discrimination}

Pascoe \& Smart-Richman 6 probably provided the most elucidative and comprehensive conceptual model for explaining the relations between discrimination and health outcomes. Discriminatory experiences, especially because they represent frequently unpredictable and difficult-to-control forms of stress 6,7, can affect health through three main mechanisms:

1. First, discriminatory experiences can have a direct effect, leading to the manifestation of adverse mental health conditions such as depressive symptoms, anxiety, and decreased subjective well-being, among others. Negative mental health states by themselves constitute adverse health outcomes, which can also contribute to worse physical health;

2. The pathological effects of discrimination can also be mediated by the psycho-physiological alterations they cause, including negative emotional states, increased and wider variability in the heart rate, chronic production of hormones involved in the response to stress (e.g. cortisol), etc.; and

3. Finally, discriminatory experiences can influence health-related behaviors. In this case, discrimination leads individuals to adopt unhealthy behaviors or reduce their participation in healthy behaviors.

In the case of the second mechanism, stress caused by discriminatory experiences can result in premature cell aging, contribute to early physical deterioration of the body, and deregulate multiple biological systems 7 . Discriminatory experiences have been interpreted as factors that increase the human body's allostatic overload 18 , given that they represent stressful events that are often repetitive or chronic.

As for the third mechanism, adverse health behaviors can manifest as strategies for coping with discriminatory experiences 7 . There is relatively consistent evidence of the relations between discrimination and smoking and consumption of alcoholic beverages and illicit drugs 6 - which potentially represent ways of coping with the stress of discriminatory experiences or with their anticipation (vigilance).

Beyond these causal mechanisms, it has been suggested that the relations between discriminatory experiences and health conditions can be modified by other factors. These include social support, coping strategies, and group identity issues, among others 4,5,6,7. For example, the availability of friends or family members to talk about the discriminatory experiences could help reestablish self-confidence, preventing negative mental health outcomes like depression 6 .

Meanwhile, the effect of discriminatory experiences on health conditions can also vary according to the respective coping strategies. Studies suggest that active coping with discriminatory experiences, such as confronting the perpetrator and actively seeking social support, can diminish the stressful effects of discrimination ${ }^{6}$. Coping strategies focused on emotions, frequently manifested as compulsive eating or alcohol and drug use, can increase the risk of obesity, besides making individuals dependent on the use of alcohol and drugs. Generally, however, evidence shows that the effect of coping strategies on the relationship between discrimination and health depends on the socio-cultural context, and that such strategies are only effective against less intense discriminatory events 5,6 .

Finally, strong links with certain group identities can lessen the stress of discrimination, preventing negative stereotypes from affecting individual self-image. However, a strong link to group identity can also leave individuals in a state of vigilance towards discriminatory experiences, potentially increasing the perception and reporting of such events 5,6 .

\section{Health conditions frequently evaluated in relation to discrimination}

Studies on mental health conditions predominate in the literature on relations between discrimination and health 1,5 , including such outcomes as anxiety, overall well-being, psychological stress, schizophrenia, loss of cognitive function, psychiatric disorders, behavioral problems, and others 4,5. Almost without exception, studies on discrimination and mental health problems 
report a direct and strong association between these two events or situations $1,4,5,6,7$. This relationship appears to be consistent for all the mental health outcomes and is not modified by gender or "racial" or ethnic classification 6 . Recent discrimination also appears to be more important than chronic or lifetime discrimination for mental health conditions 6 . However, the relations (over the lives of individuals) between experiences of discrimination and their perception and reporting, and mental health issues, are more complex (bi-directional, for example) than the conventional analytical methods have allowed capturing.

There are also relatively frequent studies on the possible effects of discrimination on blood pressure. There is a longstanding interest in the relationship between discrimination and hypertension $2,3,8$, as well as with cardiovascular outcomes in general 19 , given that acute stressful experiences are associated with an increase in blood pressure, especially in studies with participants in controlled experimental situations 3,7,8. However, the mechanisms by which discrimination can result in chronically elevated blood pressure remain unclear. These patterns of association (with blood pressure) are complex and controversial in the literature - absence of associations and associations only observed in specific population strata have been reported 7 .

Finally, the behaviors and other health conditions commonly investigated for their association with discrimination include self-rated overall health status, alcohol use and abuse, smoking, illicit drug use, healthy behaviors (regular sleep, a diet rich in vegetables, fruit, and greens, and physical exercise), and adherence to medical prescriptions (appointments, medications) 4,5,7. Adverse outcomes in relation to these aspects are consistently and directly associated with discriminatory experiences, and the strongest associations have been observed in females 6 .

\section{Measuring discrimination in epidemiological studies}

The main methodological strategy by which discrimination has been operationalized in epidemiological studies is the inclusion of questions in surveys, asking participants about experiences of unfair treatment at different levels and in different life domains. A systematic literature review conducted by the authors of this study and other collaborators, published in 2010 9, evaluated 24 of the 27 existing questionnaires for measuring victimization from racial discrimination in epidemiological surveys.
We observed that the instruments have been developed relatively recently (mostly in the last 12 years), and that they are still in their initial stages of validation and refinement. Nearly all (23) of the questionnaires were from the United States, mostly focusing on Black individuals. These instruments frequently included fewer than 30 questions, and the most common method for approaching the interviewees was self-completion of the questionnaires.

As discussed above, the theoretical references most commonly used in the development of the questionnaires have theories and evidence in common on the psycho-neuro-endocrine consequences of sources of stress and strategies for coping with them. The instruments were thus developed to assess not only discrimination (a specific form of stress), but also correlated constructs, such as behavioral and emotional strategies to cope with this experience.

In general, the reviewed questionnaires showed good psychometric properties, thus conferring reasonable validity and reliability to their measurement of discriminatory experiences 9 . However, some limitations were also identified. In particular, the questionnaires approached the interviewees as if the latter were always capable of deciphering the multifaceted nature of the discriminatory experiences. It was frequently assumed that respondents were capable of clearly identifying the reason for their discrimination and the instruments tended to ignore the possibility that racial discrimination could be combined with other types, like gender and classbased, for example.

In addition, there was a relative lack of conceptual clarity, since the terms discrimination, racism, and prejudice were often used imprecisely and interchangeably during the elaboration of the instruments. Finally, few instruments were developed on the basis of the recommendation for preparing a construct map prior to formulating the questions that it was supposed to contain. This may have jeopardized the measurement of the discriminatory experiences, given that such a map allows the instrument to include an adequate scope for the phenomenon. In the case of discrimination, the construct map should correspond to a theoretical elaboration of how the phenomenon manifests itself, specifying a gradient of intensity depicting both milder and more intense forms. 


\section{Proposal for measuring discrimination in Brazilian epidemiological studies}

Given the above-mentioned weaknesses and the predominance of questionnaires from the United States, the PhD dissertation recently presented by this article's lead author proposes an instrument for measuring the phenomenon of discrimination in Brazil 10. Preceded by pioneering studies by Faerstein et al. 20 and Santana et al. 21, the point of departure for the development of the Brazilian questionnaire was the emphasis on interactions between different types of discrimination, according to the theoretical perspective of intersectionality 22 , as well as the definition of a construct map.

Considering the challenge of developing such a questionnaire in a country marked by regional differences and important social inequalities, the questionnaire was initially conceived and evaluated in a specific population, namely a group of university students in the city of Rio de Janeiro, in Southeast Brazil.

The instrument was limited to the evaluation of explicit discrimination, corresponding to single acts of discrimination committed by individuals on the basis of their prejudices. This type of discrimination encompasses a set of behaviors with a gradient of intensity 23 , in which the milder forms include verbal antagonism and avoidance. The extreme forms involve segregationist practices, physical assault, and extermination of groups or individuals.

Based on the definition of the construct and its map, a systematic literature review was conducted of questionnaires concerning discrimination ${ }^{9}$, besides a qualitative study 24 to evaluate the meaning assigned to discrimination by members of the study population, verifying the pertinence of this construct within the respective socio-cultural context. The stages provided backing 9,24 for elaborating the questions, which were subsequently evaluated by six researchers on the theme in Brazil and one in the United States, as to the form, content, and scope of the construct to be measured.

Next, the instrument was submitted to pretest sessions, using the cognitive interview technique with 10 volunteers. A pilot study was also conducted with 15 undergraduate students from different courses in the same university. This stage allowed defining a script for approaching the interviewees and the identification of residual problems in their understanding of specific questions.

Once the suggestions for changes had been incorporated, based on the results of the cognitive interviews and pilot study, a final version of the instrument was produced, to be applied to 424 individuals, using the self-completion modality. The questionnaire on discriminatory experiences was applied again 15 days later in $13 \%(n=55)$ of the sample. The final version asks about experiences with specific differential treatments, without specifying a recall period for their occurrence. The answer to each of the 18 items is recorded using a Likert 4-point ordinal scale.

Interviewees that answer affirmatively to the above-mentioned questions are instructed to respond to three more sub-items referring to each of the target situations. The first sub-item includes one or more reasons for the differential treatment (socioeconomic status and/or social class, color or race, physical disability, etc.) and the other two investigate the degree of discomfort caused by the experience, as well whether the event was attributed to discrimination.

This version of the questionnaire then underwent a preliminary psychometric assessment for its dimensionality, reliability (test-retest and internal consistency), and construct validity (convergent and by extreme groups). The exploratory factor analysis corroborated the hypothesis of unidimensionality. The questionnaire's internal consistency, evaluated by Cronbach's alpha, was 0.8 , and the test-retest reliability was greater than 0.5 for 14 of the 18 items according to the weighted kappa coefficient. However, some questions in the questionnaire showed a low percentage of affirmative answers.

The scale's score was statistically higher (indicating greater exposure to discrimination) among socially underprivileged individuals (self-classified as Brown or Black, females, those admitted to the university through quotas, and those with worse socioeconomic status). This score was also associated with adverse health behaviors and conditions (smoking, common mental disorders, and negative self-rated health).

The preliminary results suggest that the questionnaire's performance is satisfactory for evaluating discriminatory experiences. However, it needs to be adapted for use in other research contexts. In these new contexts, the items that displayed low variability, as well as other unsatisfactory psychometric indicators, could be assessed according to the need for their reformulation or even their replacement with questions that occupy the same space on the conceptual map. New psychometric evaluations of the instrument, including discriminant construct validation and more rigorous techniques like confirmatory factor analyses, should be performed in the future. The authors urge interested researchers to submit the instrument to new psychometric evaluations and pertinent adaptations. 


\section{Conclusions}

In conclusion, discrimination has been increasingly identified as a risk factor for adverse health conditions and behaviors, based on the assumption that it represents a specific source of stress for individuals. However, progress in knowledge in this area depends both on the theoretical and empirical link between interpersonal and institutional discrimination, internalized racism, and related constructs (such as stigma and stereo- type) 17 and on dealing with issues linked to measurement of the phenomenon. In its measurement, studies should prioritize the definition of a construct map and the simultaneous evaluation of different levels and motivations in the occurrence of discrimination. The joint exploration of these aspects will provide a broader understanding of discriminatory patterns and their consequences for health, thus increasing our ability to reduce their occurrence in society.

\section{Resumo}

Abordam-se aspectos conceituais e metodológicos das relações entre discriminação e saúde, sob uma perspectiva epidemiológica. São revisadas definições de discriminação, construtos correlatos e apresentadas as teorias subjacentes à interpretação de suas associações com saúde. Discutem-se os instrumentos desenvolvidos para aferição da discriminação e uma proposta para sua operacionalização em inquéritos epidemiológicos brasileiros. Enquanto fonte de estresse psicossocial relativamente imprevisível e de difícil controle, a discriminação tem sido consistentemente associada com piores condições/comportamentos em saúde, sobretudo transtornos mentais, tabagismo e uso de álcool. Entretanto, avanços na área dependem, em parte, do enfrentamento de questões vinculadas à aferição do fenômeno, como a definição de um mapa do construto e a necessidade de avaliar diferentes discriminações simultaneamente. A exploração desses aspectos propiciará uma compreensão mais ampla da discriminação e de suas consequências sobre a saúde, aumentando nossa capacidade de reduzir sua ocorrência na sociedade.

Preconceito; Estudos Epidemiológicos; Causalidade; Nível de Saúde; Psicometria

\section{Contributors}

J. L. Bastos was responsible for conceiving the study and writing the article. E. Faerstein contributed to the conceptualization of the text and its critical revision.

\section{Acknowledgments}

The authors wish to thank Aluísio J. D. Barros for his supervision and intellectual collaboration in the $\mathrm{PhD}$ dissertation that led to part of this article. The research was partially funded by FAPERJ (grant E-26/110.315/2007) and CNPq (grant 482537/2009-4). J. L. Bastos received funding from CAPES and CNPq (PhD scholarship) from March 2007 to July 2010. 


\section{References}

1. Williams DR, Williams-Morris R. Racism and mental health: the African American experience. Ethn Health 2000; 5:243-68.

2. Williams DR, Neighbors H. Racism, discrimination and hypertension: evidence and needed research. Ethn Dis 2001; 11:800-16.

3. Brondolo E, Rieppi R, Kelly KP, Gerin W. Perceived racism and blood pressure: a review of the literature and conceptual and methodological critique. Ann Behav Med 2003; 25:55-65.

4. Williams DR, Neighbors HW, Jackson JS. Racial/ ethnic discrimination and health: findings from community studies. Am J Public Health 2003; 93:200-8.

5. Paradies Y. A systematic review of empirical research on self-reported racism and health. Int J Epidemiol 2006; 35:888-901.

6. Pascoe EA, Smart-Richman L. Perceived discrimination and health: a meta-analytic review. Psychol Bull 2009; 135:531-54.

7. Williams DR, Mohammed SA. Discrimination and racial disparities in health: evidence and needed research. J Behav Med 2009; 32:20-47.

8. Brondolo E, Love EE, Pencille M, Schoenthaler A, Ogedegbe G. Racism and hypertension: a review of the empirical evidence and implications for clinical practice. Am J Hypertens 2011; 24:518-29.

9. Bastos JL, Celeste RK, Faerstein E, Barros AJ. Racial discrimination and health: a systematic review of scales with a focus on their psychometric properties. Soc Sci Med 2010; 70:1091-9.

10. Bastos JL. Desigualdades "raciais" em saúde: medindo a experiência de discriminação auto-relatada no Brasil [PhD Dissertation]. Pelotas: Universidade Federal de Pelotas; 2010.

11. Williams DR, Collins C. Racial residential segregation: a fundamental cause of racial disparities in health. In: LaVeist TA, editor. Race, ethnicity and health: a public health reader. San Francisco: Jossey-Bass; 2002. p. 369-90.

12. Williams DR, Mohammed SA, Leavell J, Collins C. Race, socioeconomic status, and health: complexities, ongoing challenges, and research opportunities. Ann N Y Acad Sci 2010; 1186:69-101.

13. Outhwaite $\mathrm{W}$, Bottomore T. O dicionário do pensamento social do século XX. Rio de Janeiro: Jorge Zahar Editor; 1996.
14. Allport GW. The nature of prejudice. Cambridge: Perseus Books; 1979.

15. Dovidio JF, Hewstone M, Glick P, Esses VM. Prejudice, stereotyping and discrimination: theoretical and empirical overview. In: Dovidio JF, Hewstone M, Glick P, Esses VM, editors. The SAGE handbook of prejudice, stereotyping and discrimination. London: Sage; 2010. p. 3-28.

16. Taguieff P-A. O racismo. Lisboa: Instituto Piaget; 1997.

17. Stuber J, Meyer I, Link B. Stigma, prejudice, discrimination and health. Soc Sci Med 2008; 67:351-7.

18. Green TL, Darity Jr. WA. Under the skin: using theories from biology and the social sciences to explore the mechanisms behind the black-white health gap. Am J Public Health 2010; 100 Suppl 1:S36-40.

19. Wyatt SB, Williams DR, Calvin R, Henderson FC, Walker ER, Winters K. Racism and cardiovascular disease in African Americans. Am J Med Sci 2003; 325:315-31.

20. Faerstein E, Chor D, Werneck G, Lopes CS, Lynch JW, Kaplan G. Race and perceived racism, education, and hypertension among Brazilian civil servants. Am J Epidemiol 2004; 159:S35.

21. Santana V, Almeida-Filho N, Roberts R, Cooper SP. Skin colour, perception of racism and depression among adolescents in urban Brazil. Child Adolesc Ment Health 2007; 12:125-31.

22. Crenshaw KW. The intersection of race and gender. Mapping the margins: intersectionality, identity politics, and violence against women of color. In: Crenshaw KW, Gotanda N, Peller G, Thomas K, editors. Critical race theory: the key writings that formed the movement. New York: New Press; 1995. p. 357-83.

23. Blank RM, Dabady M, Citro CF. Measuring racial discrimination: panel on methods for assessing discrimination. Washington DC: National Academies Press; 2004.

24. Bastos JL, Goncalves H, Faerstein E, Barros AJ. Experiências de discriminação entre universitários do Rio de Janeiro. Rev Saúde Pública 2010; 44:28-38.

Submitted on $11 / \mathrm{Jul} / 2011$

Approved on 04/Aug/2011 